\title{
Genetic variation in the CYP2B6 Gene is related to circulating 2,2',4,4'-tetrabromodiphenyl ether (BDE-47) concentrations: an observational population-based study
}

\author{
Johanna Penell ${ }^{1}$, Lars Lind ${ }^{2}$, Tove Fall ${ }^{3}$, Anne-Christine Syvänen ${ }^{4}$, Tomas Axelsson ${ }^{4}$, Per Lundmark ${ }^{4}$, \\ Andrew P Morris ${ }^{5}$, Cecilia Lindgren ${ }^{5}$, Anubha Mahajan ${ }^{5}$, Samira Salihovic ${ }^{6}$, Bert van Bavel ${ }^{6}$, Erik Ingelsson ${ }^{3,5}$ \\ and P Monica Lind ${ }^{1 *}$
}

\begin{abstract}
Background: Since human CYP2B6 has been identified as the major CYP enzyme involved in the metabolism of 2,2',4,4'-tetrabromodiphenyl ether (BDE-47) and that human 2B6 is a highly polymorphic CYP, with known functional variants, we evaluated if circulating concentrations of a major brominated flame retardant, BDE-47, were related to genetic variation in the CYP2B6 gene in a population sample.

Methods: In the population-based Prospective Investigation of the Vasculature in Uppsala Seniors (PIVUS) study (men and women all aged 70), 25 single nucleotide polymorphisms (SNPs) in the CYP2B6 gene were genotyped. Circulating concentrations of BDE-47 were analyzed by high-resolution gas chromatography coupled to high-resolution mass spectrometry (HRGC/ HRMS).
\end{abstract}

Results: Several SNPS in the CYP2B6 gene were associated with circulating concentrations of BDE-47 $\left(P=10^{-4}\right.$ to $\left.10^{-9}\right)$. The investigated SNPs came primarily from two haplotypes, although the correlation between the haplotypes was rather high. Conditional analyses adjusting for the SNP with the strongest association with the exposure (rs2014141) did not provide evidence for independent signals.

Conclusion: Circulating concentrations of BDE-47 were related to genetic variation in the CYP2B6 gene in an elderly population.

Keywords: 2,2',4,4'-tetrabromodiphenyl ether, BDE-47, CYP, Elderly, Epidemiology, Gene, SNP

\section{Background}

Polybrominated diphenyl ethers (PBDEs) are flame-retardant chemicals that are commonly used in textiles such as clothes and furniture, electronic equipment, plastics and various inflammable materials to prevent fires $[1,2]$. The Stockholm Convention in 2009 listed penta- and octaPBDE as new persistent organic pollutants and classified them as materials requiring international regulation [3]. The use of certain PBDEs has been restricted or banned in the European Union since 2004. However, due to their

\footnotetext{
*Correspondence: Monica.Lind@medsci.uu.se

1 Department of Medical Sciences, Occupational and Environmental Medicine, Uppsala University, Uppsala, Sweden

Full list of author information is available at the end of the article
}

persistence in the environment these chemicals have become ubiquitous environmental pollutants and can be detected in air, soil and water. Despite the growing concern there is, in general, little information about the risks these chemicals pose to public health [4]. Concentrations of serum PBDEs has been associated with self-reported hand-to-mouth behaviors, including biting nails and licking fingers, and ownership of a largescreen TV [5]. PBDEs have a neurotoxic potential and higher concentrations of PBDE have been associated with various adverse outcomes in children such as impaired cognitive and behavior development [6]. Furthermore, associations between PBDEs (BDE 47, 99 and 100) in house dust and hormone levels in men have 
been reported [7]. Considering the severe adverse health effects reported in relation to PBDE concentrations, it is of outmost importance to increase the understanding of PBDE metabolism. 2,2'4,4'-tetrabromodiphenyl ether (BDE-47) is the most commonly detected PBDE congener in human serum worldwide [8-13]. We have previously reported concentrations of BDE-47 in the majority of elderly men and women in a population-based sample [14]. We use this congener as a marker for PBDE exposure as it is frequently detected and included in a large number of biomonitoring studies and thus valid for comparison.

Enzymes produced from the cytochrome P450 (CYP) genes are primarily found in the liver and they are involved in the synthesis and metabolism of various molecules and chemicals within cells [15]. Apart from the role CYP enzymes play in the synthesis of steroid hormones, certain fats, and acids used to digest fats, they are also involved in metabolizing endogenous toxins and xenobiotics for example pharmaceuticals and environmental pollutants such as PBDEs [16].

The metabolism of brominated flame retardants has been extensively studied in the experimental setting. In human liver microsomes, CYP2B6 plays a key role in the biotransformation of many xenobiotics [17] and has been identified as the major CYP enzyme involved in the metabolism of BDE-47 [18,19]. Furthermore, in rat hepatoma cells and in zebrafish embryos, a BDE-47 mixture enhanced $C Y P 2 B$ gene expression [20]. Also, studies with recombinant CYPs support CYP2B6 as the major CYP in CYP-mediated metabolism of BDE-47 [19].

The activity of an enzyme and the gene expression may be modified by single nucleotide polymorphisms (SNPs) [17]. The CYP2B6 sequence carries high variance $[21,22]$ and up to today at least 29 variants have been described [23]. A majority of the variation in CYP450 activity relates to SNPs in the CYP450 gene locus [21]. Certain SNPs in the region have a large impact on CYP activity [24] such as altering the composition of transcribed protein [21] and affect the interindividual differences in xenobiotic metabolism [25]. Several single nucleotide polymorphisms (SNPs) in the P450 system have been reported to influence the activity of different CYP enzymes that are important for metabolism of both endogenous, exogenous and xenobiotic compounds $[21,25,26]$. For example, a specific genotype in $C Y P 2 B 6$ has been shown to affect the xenobiotic metabolism of an anti-HIV agent [27]. Also, effects of certain SNPs have been reported, for example rs2279345 was found to be associated with a higher clearance and a lower plasma concentration of methadone [28]. On the contrary, several SNP polymorphisms (including rs8192719) were underrepresented in the low-methadone group suggesting decreased CYP2B6 activity [29]. When 13 SNPs in CYP2B6 (five of which are included in this study) were investigated regarding plasma efavirenz (a HIV-medication) concentrations, 3 SNPs (rs10403955 (not investigated in this study), rs2279345 and rs8192719) were found representative of the 11 SNPs associated with plasma efavirenz concentrations [30]. There is evidence on species differences in the metabolism of BDE-47 [16]. However, for humans, there is a lack of knowledge regarding the impact of SNPs in CYP2B6 on BDE-47 metabolism and plasma concentrations in the real-life setting. Such information may provide clinically useful information on recommendations to reduce exposure to $\mathrm{BDE}-47$ in certain susceptible individuals. This study investigated whether the experimental findings on the associations between SNPs in $C Y P 2 B 6$ regarding $\mathrm{BDE}-47$ concentrations could be repeated in an epidemiological cross-sectional observational study in humans. We used data from the Prospective Investigation of the Vasculature in Uppsala Seniors (PIVUS) study to study if SNPs in cytochrome P450 2B6 (CYP2B6) gene, encoding the only enzyme in the $C Y P 2 B$ subfamily that is expressed in the liver in humans, were related to circulating concentrations of BDE-47 in men and women by applying multivariable linear regression model techniques.

\section{Methods}

\section{Study population}

All men and women aged 70 and living in the community of Uppsala, Sweden at enrolment between April 2001 and June 2004 were eligible for the study. Two thousand and twenty five participants were randomly selected from the national register of residence and invited to the study. A total of 1016 subjects participated (participation rate $50.1 \%)$. The study was approved by the Ethics Committee of the University of Uppsala (diary number 2007/302) and all the participants gave their written informed consent.

All subjects were investigated in the morning after an over-night fast. No medication or smoking was allowed after midnight. The participants also answered a questionnaire about their medical history, regular medication, and smoking and exercise habits. Approximately $10 \%$ of the cohort reported a history of coronary heart disease, 4\% reported stroke and 9\% reported diabetes mellitus. Almost half the cohort reported some sort of cardiovascular medication (45\%), with antihypertensive medication being the most prevalent (32\%). Fifteen percent reported use of statins, while oral antiglycemic drugs and insulin use were reported in 6 and $2 \%$, respectively. Eleven percent were current smokers, see reference [31] for details. Blood samples were taken through an arterial cannula inserted in the brachial artery [31].

\section{BDE-47 analysis}

BDE-47 concentrations were measured in stored plasma samples collected at the baseline investigation using a 
high-resolution gas chromatograph $(6890 \mathrm{~N}$, Agilent Technologies, Atlanta, GA, USA) coupled to a high-resolution mass spectrometer (Micromass Autospec Ultima,Waters, Milford, MA, USA) (HRGC/HRMS) based on the method by Sandau and co-workers [32] with some modifications. A more detailed description of the analysis in this sample has previously been presented [33].

In 255 (28\%) of the persons included in the analyses, BDE-47 was below the detection limit $(9.2 \mathrm{pg} / \mathrm{ml})$. In those subjects the value was set to the detection limit divided by the squared root of two, which is a commonly used method to impute censored data [34]. This has been recommended when relatively few data are below the detection limit or where data are not highly skewed [35]. Therefore, this procedure has been widely used because of its simplicity and ease of operation and produce low bias and moderate precision using environmental data [36]. Lipid-normalized values (ng/g lipid) for BDE47 were used in the analysis. The total amount of lipids in each plasma sample was obtained by using an established summation formula based on serum cholesterol and serum triglyceride concentrations [37]. In the next step, using the wet-weight concentration of the BDE-47 as nominator and the amount of lipids as the denominator, lipid-normalized BDE-47 values were obtained.

\section{Genotyping}

A total of $25 \mathrm{SNP}$ in the P450 enzyme CYP2B6 gene were genotyped using the Illumina OmniExpress chip at Wellcome Trust Sanger Institute, Oxford, UK (20 SNPs) and a custom Illumina Golden Gate assay at the SNP\&SEQ Technology Platform at Uppsala University, Uppsala, Sweden (http://www.genotyping.se) (5 SNPs). Sample exclusion criteria included: 1) genotype call rate $<95 \%$; 2 ) heterozygosity >3 standard deviations (SDs); 3) gender discordance; 4) duplicated samples; and 5) no identityby-descent match. SNP exclusion criteria included: 1) monomorphic SNPs; 2) Hardy-Weinberg equilibrium (HWE) p-value $<1 \times 10-6$ for the GWAS selected SNPs and $P<0.05$ for the directly genotyped SNPs; 3$)$ genotype call rate $<0.99$ for SNPs with minor allele frequency $(\mathrm{MAF})<5 \%$, or $<0.95$ for SNPs with $\mathrm{MAF} \geq 5 \%$. One SNP (rs1272165) failed to meet SNP exclusion criteria 3, and hence was excluded from further analyses.

Using the European 1000 Genomes genotypes as reference (population codes: CEU, FIN, GBR, IBS, TSI), the gene region for $C Y P 2 B 6$, length $41.9 \mathrm{~kb}$, contained 128 SNPs with MAF $>5 \%$. The SNPs genotyped in this study could tag 110 of these at $\mathrm{r}^{\wedge} 2>0.8$. All SNPs genotyped in the study were present in the 1000 Genomes data.

\section{Statistics}

BDE-47 concentrations were transformed to the natural logarithm scale prior to analysis to account for the non- normal distribution. Relationships between the CYP2B6 SNPs and BDE-47 concentrations were evaluated by linear regression analysis with BDE-47 as dependent linear variable adjusting for gender and the principal components 1 and 2 (derived from EIGENSTRAT based on GWAS data). Each SNP was coded as 0, 1 or 2 alleles of the minor allele and evaluated in a separate multivariable model assuming additive allele effect. The p-values were adjusted to account for multiple testing (see below). Principal components were included to account for any possible population stratification in the study population that may bias the relationships under study. To investigate if there were several independent signals, the analyses were also performed for the remaining SNPs when adjusting for the lead (i.e. lowest p-value) SNP in addition to gender and the principal components 1 and 2 (i.e. conditional analysis). To investigate if associations between BDE-47 and SNP were stable regardless if the BDE-47 concentrations were above or below the detectible limit, logistic regression analysis with a binary variable for non-detectable/detectable BDE-47 concentra tions as dependent variables and the SNPs, gender and the principal components 1 and 2 as independent variables was performed. Since 24 tests were performed in the main linear and logistic regression analyses, we adjusted the critical p-value accordingly using the Bonferroni correction ( $\mathrm{p}$-value $=0.05 / 24=0.0021$ for statistical significance). The use of this strict threshold, not taking into account the high correlations of SNPs within the same LD blocks which would warrant a more liberal threshold, was motivated by the lack of suitable replication samples (see further in the Discussion section).

\section{Results}

The number of study subjects included in the analyses was 924 of which 462 were women (50\%). The mean value for the lipid-normalized BDE-47 was 4.3 (SD 20.1, range $0.6-476) \mathrm{ng} / \mathrm{g}$ lipid. The median value was 2.0 (1.2-3.0 for $25^{\text {th }}$ and $75^{\text {th }}$ percentile) $\mathrm{ng} / \mathrm{g}$ lipid.

The associations between 24 SNPs in the CYP2B6 gene and circulating concentrations of lipid-normalized BDE-47 are presented in Table 1. For example, in Table 1 the beta coefficient for rs2014141 versus lipid-normalized ln-transformed BDE-47 was -0.21 . This should be interpreted as that the per-allele effect of the SNP will correspond to a 0.21 decrease in $\operatorname{lnBDE}-47$ concentrations which corresponds to $\mathrm{e}^{-0.21}=19 \%$ decrease in total serum BDE-47 concentrations. Figure 1 shows the association signal plot for SNPs mapping to $C Y P 2 B 6$ with BDE-47. The haplotype structure of the CYP2B6 SNPs based on the PIVUS data is shown in Figure 2.

Circulating BDE-47 concentrations were significantly associated with several of the investigated $C Y P 2 B 6$ variants, even after taking multiple testing into account. The 
Table 1 Association between SNPs in the CYP2B6 gene and circulating lipid-normalized levels of BDE-47

\begin{tabular}{|c|c|c|c|c|c|c|}
\hline SNP $^{a}$ & position & $\begin{array}{l}\text { Minor allele/ } \\
\text { major allele }\end{array}$ & $\mathrm{MAF}^{\mathrm{b}}$ & $\begin{array}{l}\mathrm{n}_{\text {obs }} \text { in the } \\
\text { analysis }\end{array}$ & $\begin{array}{l}\text { Beta }(95 \% \mathrm{Cl}) \text { on natural } \\
\text { logaritm scale }\end{array}$ & $\begin{array}{l}\text { P-value (Bonferroni-corrected } \\
\text { p-value for significance }=0.0021 \text { ) }\end{array}$ \\
\hline rs1808682 & 41489448 & $A / G$ & 0.23 & 920 & $0.11(0.026,0.19)$ & $9.5^{*} 10^{-3}$ \\
\hline rs3760657 & 41495433 & $\mathrm{G} / \mathrm{A}$ & 0.12 & 924 & $0.16(0.058,0.27)$ & $2.5^{*} 10^{-3}$ \\
\hline rs2099361 & 41498348 & $C / A$ & 0.36 & 923 & $-0.18(-0.25,-0.11)$ & $2.8^{*} 10^{-7}$ \\
\hline rs2014141 & 41499989 & $A / G$ & 0.41 & 924 & $-0.21(-0.28,-0.14)$ & $4.9^{*} 10^{-9}$ \\
\hline rs8192711 & 41500057 & $A / G$ & 0.05 & 923 & $-0.12(-0.27,0.031)$ & 0.12 \\
\hline rs8100458 & 41500213 & $C / T$ & 0.35 & 924 & $0.17(0.10,0.24)$ & $3.4^{*} 10^{-6}$ \\
\hline rs4803415 & 41500593 & $\mathrm{~T} / \mathrm{C}$ & 0.10 & 886 & $0.19(0.08,0.30)$ & $6.9 * 10^{-4}$ \\
\hline rs8101756 & 41502522 & $C / T$ & 0.24 & 923 & $0.062(-0.018,0.14)$ & 0.13 \\
\hline rs16974799 & 41504077 & $\mathrm{~T} / \mathrm{C}$ & 0.24 & 924 & $0.062(-0.018,0.14)$ & 0.13 \\
\hline rs4803417 & 41508020 & C/A & 0.41 & 924 & $-0.21(-0.28,-0.14)$ & $4.9^{*} 10^{-9}$ \\
\hline rs10500282 & 41508442 & $C / T$ & 0.26 & 923 & $0.087(0.009,0.16)$ & 0.028 \\
\hline rs11672911 & 41508744 & $A / G$ & 0.32 & 924 & $0.17(0.10,0.25)$ & $5.6^{*} 10^{-6}$ \\
\hline rs2279345 & 41515702 & $\mathrm{~T} / \mathrm{C}$ & 0.39 & 924 & $-0.17(-0.24,-0.10)$ & $9.6^{*} 10^{-7}$ \\
\hline rs8192718 & 41515814 & $A / G$ & 0.02 & 924 & $-0.099(-0.39,0.19)$ & 0.50 \\
\hline rs6508965 & 41517688 & $\mathrm{~T} / \mathrm{C}$ & 0.39 & 924 & $-0.17(-0.24,-0.10)$ & $1.1 * 10^{-6}$ \\
\hline rs8192719 & 41518773 & $\mathrm{~T} / \mathrm{C}$ & 0.24 & 924 & $0.066(-0.012,0.14)$ & 0.10 \\
\hline rs11882450 & 41520142 & $\mathrm{G} / \mathrm{A}$ & 0.06 & 924 & $-0.095(-0.24,0.052)$ & 0.20 \\
\hline rs11673270 & 41520844 & $C / A$ & 0.24 & 924 & $0.060(-0.019,0.14)$ & 0.14 \\
\hline rs7260329 & 41521638 & $A / G$ & 0.32 & 924 & $0.17(0.093,0.24)$ & 9. $3^{*} 10^{-6}$ \\
\hline rs2291287 & 41522451 & $\mathrm{G} / \mathrm{A}$ & 0.06 & 924 & $-0.095(-0.24,0.052)$ & 0.20 \\
\hline rs1042389 & 41524153 & $\mathrm{G} / \mathrm{A}$ & 0.21 & 923 & $0.040(-0.041,0.12)$ & 0.33 \\
\hline rs1552223 & 41525952 & $\mathrm{G} / \mathrm{A}$ & 0.39 & 924 & $-0.16(-0.23,-0.092)$ & $5.0^{*} 10^{-6}$ \\
\hline rs $2113103^{c}$ & 41528667 & $A / G$ & 0.15 & 924 & $0.076(-0.018,0.17)$ & 0.11 \\
\hline rs7255904c & 41529020 & $A / G$ & 0.45 & 921 & $0.13(0.059,0.19)$ & $2.6^{*} 10^{-4}$ \\
\hline
\end{tabular}

${ }^{\mathrm{a}} \mathrm{SNP}=$ single nucleotide polymorphisms.

${ }^{\mathrm{b}} \mathrm{MAF}=$ Minor allele frequency.

'SNPs genotyped in Uppsala, others in Oxford.

The position data originates from the UCSC Genome Browser on Human February 2009 (GRCh37/hg19) and allele data originates from the genotyped SNPs

included in the study. All SNPs are located on chromosome 19.

associated SNPs came primarily from two haplotypes (Figure 2; all $\mathrm{p}=2.6^{*} 10^{-4}$ to $4.9^{*} 10^{-9}$ ). The two top SNPs rs2014141 and rs4803417 were in complete LD. The median values for the lipid-normalized BDE- 47 for 0,1 and 2 copies of the minor allele for rs2014141 were 4.3 (1.8-3.7 for $25^{\text {th }}$ and $75^{\text {th }}$ percentile), 4.8 (1.2-2.9 for $25^{\text {th }}$ and $75^{\text {th }}$ percentile) and $3.0\left(1.1-2.3\right.$ for $25^{\text {th }}$ and $75^{\text {th }}$ percentile) $\mathrm{ng} / \mathrm{g}$ lipid, respectively. Thirty five percent of the subjects had 0 copies of the minor allele whereas 17 percent had 2 copies of this allele. In addition, one SNP with MAF of 0.10 showed significant association with the outcome ( $\left.\mathrm{rs} 4803415, \mathrm{p}=6.9^{*} 10^{-4}\right)$. While close relationships were seen between the SNPs within the two haplotypes as expected, high $\mathrm{LD}\left(\mathrm{R}^{2}>\right.$ 0.90) was also observed between SNPs across the two haplotypes (Figure 2).

Conditional analyses were performed by adding one of the top SNPs (i.e. SNPs with lowest p-value from the main analyses, see Table 1), rs2014141, to the models of the other SNPs to investigate independent signals; none of the other 22 SNPs showed significant association with the BDE-47 concentrations.

Since 255 subjects showed BDE-47 concentrations below the limit of detection, we additionally performed logistic regression analysis with a binary variable for nondetectable/detectable BDE-47 concentrations as dependent variables and the SNPs, gender and the principal components 1 and 2 as independent variables in separate models for each SNP. That approach resulted in similar results as in the linear models described above, with highly significant associations between low BDE-47 concentrations and the genotypes with MAF in the 0.36-0.45 range (all $\mathrm{p}=10^{-4}$ to $10^{-6}$ )(data not shown). Figure 3 shows the relationship between the proportion of nondetectable concentrations in the sample and genotypes for one of the top SNPs (rs2014141). 


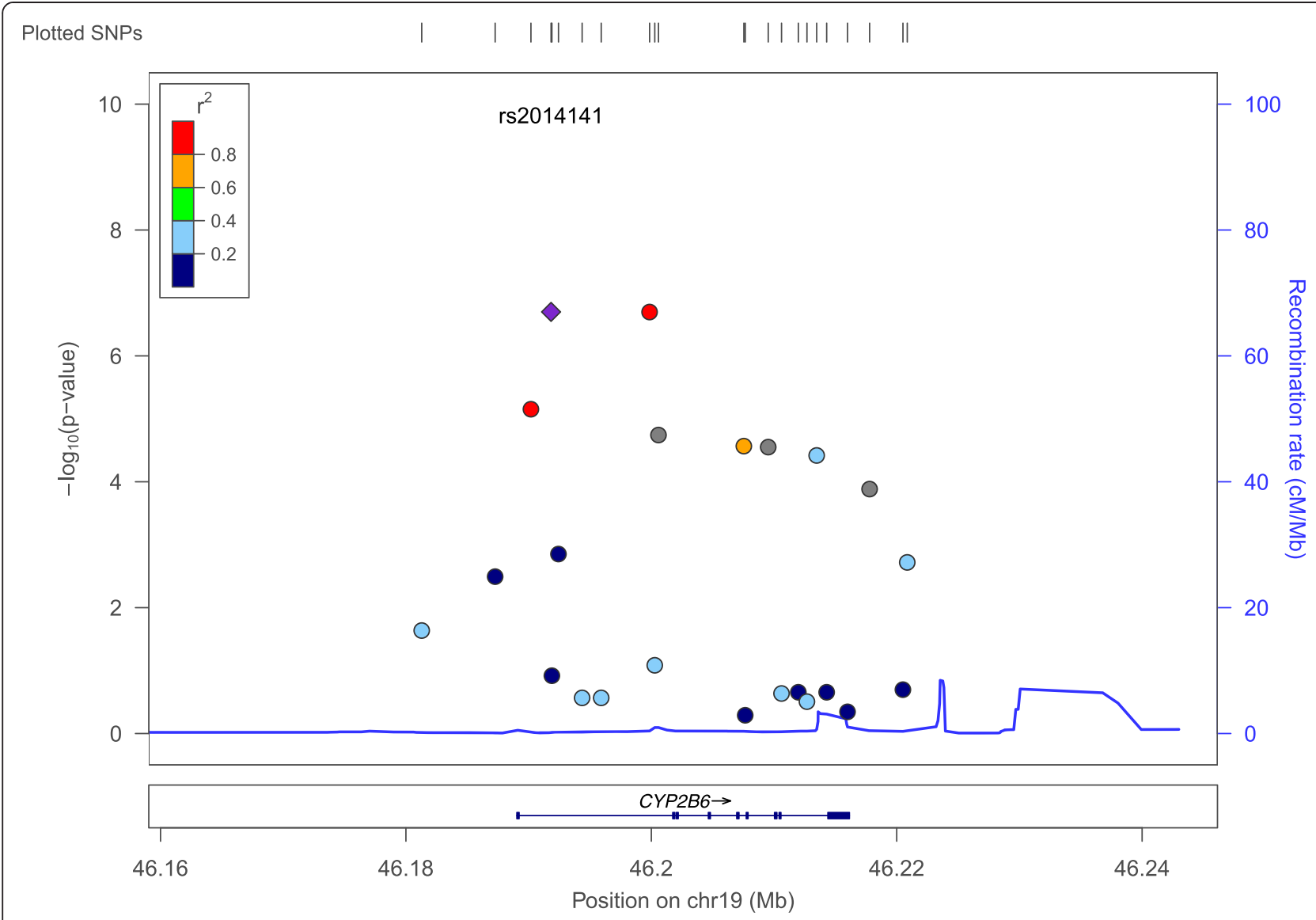

date: Mon Sep 30 05:05:32 2013

build: hg18

display range: chr19:46159043-46246141 [46159043-46246141]

hilite range: $0-0$ [0-0]

reference SNP: chr19:46191829

number of SNPs plotted: 23

\section{max P.value: 2E-7 [chr19:46191829] \\ min P.value: $5.1 \mathrm{E}-1$ [chr19:46207654]}

Figure 1 Association signal plot for SNPs mapping to CYP2B6. Each point represents a SNP in the association analysis, plotted with their p-value (on a -log10 scale) as a function of genomic position (NCBI Build 36). The lead SNP (with maximal association signal) is represented by the purple symbol. The shape of the plotting symbol corresponds to the annotation of the SNP: square for synonymous or UTR; and circle for intronic or non-coding. The colour coding of all other SNPs indicates LD with the lead SNP (estimated by CEU r2 from Phase II HapMap): red r2 $\geq 0.8$; gold $0.6 \leq r 2<0.8$; green $0.4 \leq r 2<0.6$; cyan $0.2 \leq r 2<0.4$; blue $r 2<0.2$; grey $r 2$ unknown. Recombination rates are estimated from Phase II HapMap and gene annotations are taken from the University of California Santa Cruz genome browser.

\section{Discussion}

The present study, including a homogenous population of 70 -year-old Caucasian men and women showed that genetic variation in the CYP2B6 gene was related to circulating concentrations of the brominated flame retardant BDE-47. This finding is in line with previous experimental findings that BDE- 47 was mainly bio transformed by CYP2B enzyme in human microsomes and could induce CYP2B enzymes in rats, respectively $[18,20]$. It has also been shown that BDE-47 induces CYP2B6 genes in mice and human hepatocytes, although at higher BDE-47 concentrations than generally found in humans $[38,39]$. There is yet no evidence that BDE-47 can induce CYP genes at the concentrations 

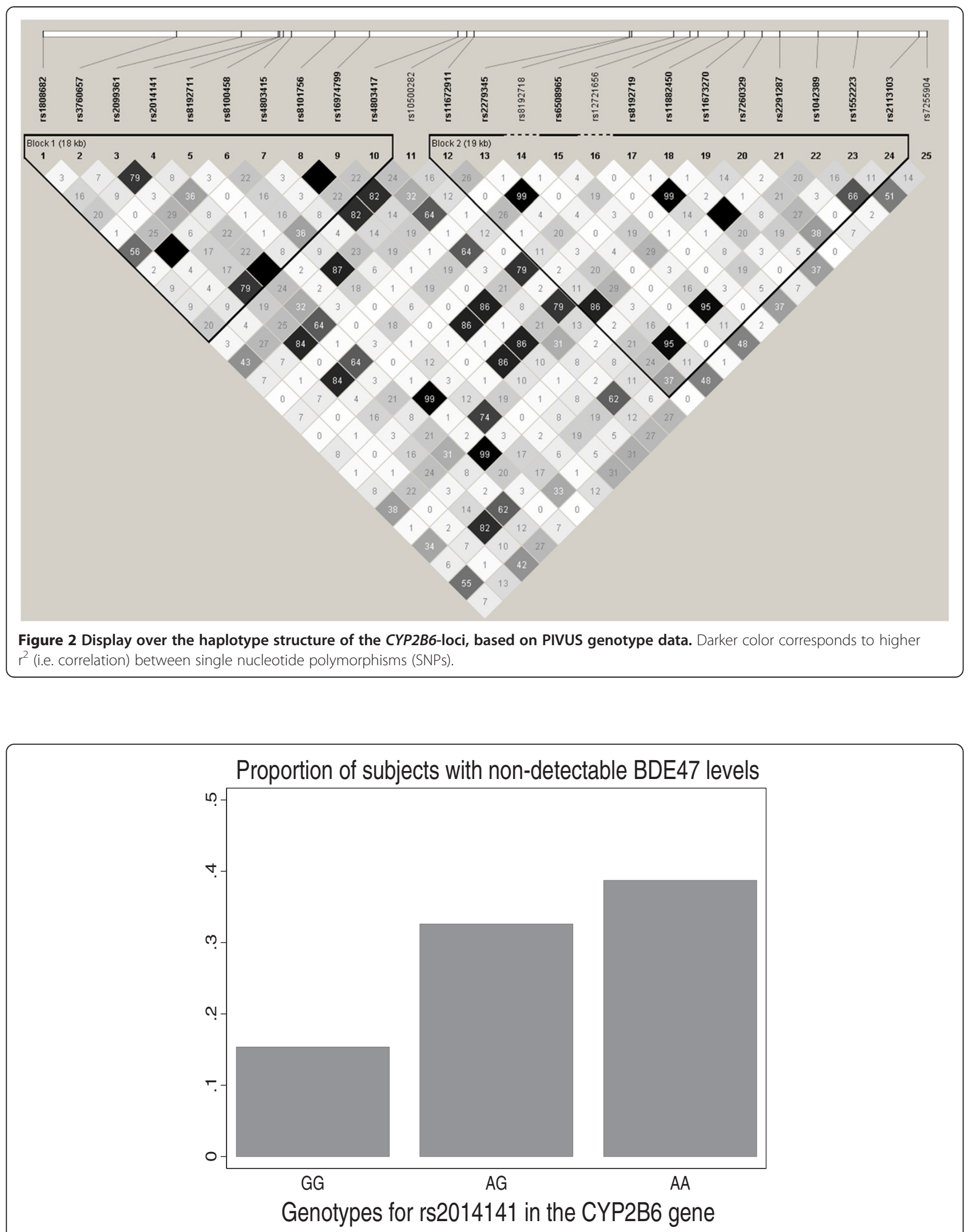

Figure 3 Proportion of subjects with non-detectable BDE-47 levels according to the rs2014141 genotype in the CYP2B6 gene. $\mathrm{N}_{\mathrm{AA} \text { allele }}=163, \mathrm{~N}_{\mathrm{AG}}$ allele $=457, \mathrm{~N}_{\mathrm{GG}}$ allele $=329$. 
found in the general human population. However, if BDE-47 can induce CYP2B6 enzymes also at lower concentration, this will have implications on human response to numerous therapeutic drugs [39]. There is also evidence that other xenobiotics may induce or modulate $C Y P 2 B 6$ in humans. For example the antiretroviral drug rilpivirine and a malaria drug were seen to inhibit CYP2B6 in vitro $[40,41]$ as well as the antiplatelet drug ticlopidine in vivo [42]. Furthermore, carnosic acid which has been suggested as a potential treatment for obesity and nonalcoholic fatty liver disease has showed increased CYP2B6 enzyme activity thus indicating a potential drug interaction with carnosic acid [43]. In the present study, the strongest associations were seen between BDE-47 concentrations and the more common variants, which are also the most well-powered relationships to find. Additional conditional analysis adjusting for one of the top SNPs did not provide evidence of multiple signals. This implies that rs2014141 and rs4803417 might lie closest to the causal variant. Allelic heterogeneity (i.e. several causal mutations on different alleles/positions within a locus) cannot, however, be excluded due to the limited sample size and hence the low power to detect low frequency signals. Since we are not aware of any other populationbased study with BDE measurements in a fairly large cohort in which also genetic analysis in CYP genes has been performed, we cannot replicate the findings in an independent cohort. Hence, we acknowledge the lack of replication as an important limitation, but believe that the study still is valuable due the high a priori probability for involvement of CYPs in the metabolism of brominated flame retardants. Also, the p-values well below the Bonferroni corrected p-values for statistical significance support the likelihood of the results not being chance findings.

Previously many studies have addressed the effect of variability in CYP2B6 on various xenobiotics $[22,25,28,44]$. Some of these studies include specific SNPs also investigated in this study. For example rs2279345 was associated with lower concentrations of methadone [28] and efavirenz plasma concentration [45] which is the same direction of the highly significant effect that is reported in this study for the intron variant rs2279345 on BDE-47 concentrations. Also rs8192719 has been reported to be related to methadone although in the opposite direction by lower CYP2B6 activity [29]. We did not see any association between this SNP and BDE-47 concentrations. Also rs1042389 has been investigated and found not be associated with response to two treatments of HIV infection [46] which mimics the no-existing relationship between this SNP and BDE-47 concentrations seen in this study. In addition, we compared the two top SNPs rs2014141 and rs4803417 identified in this study with previously known variants using HapMap release 22 and population panel CEU (http://www.broadinstitute.org/mpg/ snap/ldsearch.php). This revealed that rs2014141 has perfect LD with rs6508964 and $\mathrm{rs} 10418990\left(\mathrm{r}^{2}=1.00\right)$, and high LD with rs2099361 and rs3889806 (both $\mathrm{r}^{2}=0.87$ ). For rs4803417, the correlation pattern was similar with high LD with SNPs rs6508964 and rs10418990 $\left(r^{2}=0.93\right)$, and with rs2099361 and rs3889806 (both $\mathrm{r}^{2}=0.81$ ). The so far most commonly studied CYP2B6 SNP rs3745274 [30], which is a missense variant, where polymorphism is associated with for example lower hepatic expression and enzymatic activity for CYP2B6 [47], higher efavirenz exposure [48], plasma propofol concentrations [49] and increased breast cancer risk [50] was in low LD with the two top SNPs in this study $\left(\mathrm{r}^{2}=0.29\right)$. Similarly, two other wellstudied missense variants SNPs rs3211371 and rs2279343 associated with altered metabolism of various substrates [51] was also in low LD with the two top SNPs in this study $\left(\mathrm{r}^{2}=0.29\right)$. Many other CYP2B6 SNPs have been reported to be associated with various phenotypes, however, none were in high LD with our two top SNPs. For example, neither SNPs related to nicotine metabolism (rs8109525, $\mathrm{r}^{2}=$ 0.28) [51] or to altered expression of the CYP2B6 enzymes (e.g. the missense variants rs8192709 and rs3211371, $\mathrm{r}^{2}<$ 0.2 ) [22], nor marker SNPs for plasma efavirenz concentrations (rs10403955 and rs8192719, $\mathrm{r}^{2}=0.34$ and 0.31 , respectively ) [30] were in $\mathrm{LD}\left(\mathrm{r}^{2}<0.2\right)$ with $\mathrm{rs} 2014141$ and rs4803417.

The clinical implications of genotype polymorphism affecting BDE-47 concentrations are yet to be fully understood. We interpreted the findings in this study so that genotype may be a predictor of BDE-47 metabolism by affecting the BDE- 47 concentrations. The suggested causal pathway from genotype to BDE- 47 concentrations implies that genetic variability in the CYP2B6 gene may lead to interindividual variability in the concentrations of BDE-47. This could have clinical relevance in subgroups with genotypes associated with higher PBDE concentrations or for individuals where PBDE concentrations should be kept to a minimum. For example, this would be of interest to pregnant women and parents bearing in mind the neurotoxicological, behavior and hormone disruptive effects that have been reported to be associated with PBDE exposure [6,7]. Taking advantage of genotyping has previously been suggested for example regarding selecting anaesthetics for optimal anesthesia that reduce risk of side effects as well as undesirable actions [52]. Analogously, as SNPs have been shown to affect the pharmacokinetics and response to a HIV-treatment drug [44] we suggest that detailed knowledge on SNP may be clinically relevant also regarding PBDE concentrations and metabolism.

Cytochrome P450 enzymes account for the majority of enzymes involved in drug metabolism. Common variations (polymorphisms) in cytochrome $\mathrm{P} 450$ genes can 
affect the function of the enzymes e.g. breakdown of medications. Indeed, several single nucleotide polymorphisms (SNPs) in the P450 system have been discovered to influence the activity of different CYP enzymes. Furthermore, a recent review on variations of cytochrome P450 in different ethnic populations suggests that ethnical differences in metabolic phenotype can be explained by differences in the distributions of SNPs [21]. Important substrates for CYP2B6 include nicotine and the antidepressant and smoking cessation aid bupropion $[53,54]$. As both BDE-47 concentrations [4] and ethnic composition of the population varies across the world, assessment of the effect of BDE-47 on CYP2B6 on a wide range of exposure concentrations and different populations is relevant even though significant variation of CYP isoform activity may also occur within subgroups of a specific ethnic group [21]. In addition to being abundant in the liver, CYP2B6 is present in most regions of the brain [55]. This could be the reason why PBDE exposure has been associated with neurotoxicity and neurological diseases and could also reflect variability between individuals in response to centrally acting drugs.

The two haplotypes seen in this study agrees somewhat with earlier findings in that rs8100458 and rs2279345 were located in different haplotypes [28].

Ideally, the role of CYP induction on the metabolism of a xenobiotic, such as BDE-47, should be studied by distributing a fixed dose of the compound at a certain time point and thereafter evaluate the concentrations of the compounds in a standardized fashion. This is obviously not the case in the present observational epidemiologic study where there is no information on amount and timing of the BDE-47 exposure. However, by studying this relationship in an epidemiologic study including men and women, we may observe a relationship that more corresponds to real life settings. Furthermore, by including persons of the same age at a certain rather small time interval, we reduce variability due to age and time differences in exposure. Indeed, the major strength of the study is the rather large number of subjects with measurements of BDE-47 at the same age, which would increase the likelihood of establishing true relationships. A limitation of this study is that approximately one fourth of the sample had circulating concentrations of BDE-47 below the detection level. However, the additional analysis comparing observations with non-detectable and detectable concentrations of BDE-47 yielded similar results as the main findings indicating robustness of the study findings.

Future research on effects of BDE-47 exposure on humans may include proteome changes or differential protein expressions to determine if the molecular machinery could be adjusted to cope with e.g. BDE-47 exposure.

\section{Conclusions}

Circulating concentrations of BDE-47 were related to genetic variation in the CYP2B6 gene in an elderly population. Future research may investigate the protein expression pattern related to BDE exposure and determine if genetic adaptation to improve the resistance to $\mathrm{BDE}$ may occur in human populations as a response to this exposure.

\section{Abbreviations}

BDE-47: 2,2',4,4'-tetrabromodiphenyl ether; PIVUS: Prospective Investigation of the Vasculature in Uppsala Seniors; HRGC/HRMS: High-resolution gas chromatography/high-resolution mass spectrometry; PBDEs: Poly brominated diphenyl ethers; SNPs: Single nucleotide polymorphisms; WHO: World Health Organization; HWE: Hardy-Weinberg equilibrium; MAF: Minor allele frequency; $\mathrm{Cl}$ : Confidence interval.

\section{Competing interests}

The authors have no competing financial interests.

\section{Authors' contributions}

PML and LL conceived the project. El contributed to the design of the study and the critical revision of the manuscript for important intellectual content. $\mathrm{LL}$ is the principal investigator of the Prospective Investigation of the Vasculature in Uppsala Seniors (PIVUS) study and performed the initial data analysis. PML and LL wrote the initial draft of the manuscript and contributed to the critical revision of the manuscript for important intellectual content. JP performed data analysis, had full access to all the data in the study and takes responsibility for the integrity of the data and the accuracy of the data analysis, and contributed to the critical revision of the manuscript for important intellectual content. S.S. and B.v.B. performed POPs laboratory analyses and contributed to the critical revision of the manuscript for important intellectual content. TF and APM carried out the association signal plot and the haplotype signal plot and contributed to the critical revision of the manuscript for important intellectual content. APM, CL, AM, AS, TA and PL carried out the genotyping and contributed to the critical revision of the manuscript for important intellectual content. All authors read and approved the final manuscript.

\section{Acknowledgements}

This study was supported by the Swedish Research Council, the Swedish Research Council for Environment, Agricultural Sciences and Spatial Planning, and the Wellcome Trust (grant numbers WT098017, WT090532 and WT064890).

\section{Author details}

'Department of Medical Sciences, Occupational and Environmental Medicine, Uppsala University, Uppsala, Sweden. ${ }^{2}$ Department of Medical Sciences, Cardiovascular Epidemiology, Uppsala University, Uppsala, Sweden.

${ }^{3}$ Department of Medical Sciences, Molecular Epidemiology and Science for Life Laboratory, Uppsala University, Uppsala, Sweden. ${ }^{4}$ Department of Medical Sciences, Molecular Medicine and Science for Life Laboratory, Uppsala University, Uppsala, Sweden. ${ }^{5}$ Wellcome Trust Centre for Human Genetics, University of Oxford, Oxford, UK. ${ }^{6}$ MTM Research Centre, School of Science and Technology, Örebro University, Örebro, Sweden.

Received: 13 November 2013 Accepted: 28 April 2014

Published: 8 May 2014

\section{References}

1. WHO: World Health Organization. Environmental health criteria 192: Flame retardants: a general introduction. 1997.

2. Segev O, Kushmaro A, Brenner A: Environmental impact of flame retardants (persistence and biodegradability). Int J Environ Res Public Health 2009, 6:478-491.

3. WHO: World Health Organization. Persistent organic pollutants impact on child health. 2010.

4. Birnbaum LS, Staskal DF: Brominated flame retardants: cause for concern? Environ Health Perspect 2004, 112:9-17. 
5. Buttke DE, Wolkin A, Stapleton HM, Miranda ML: Associations between serum levels of polybrominated diphenyl ether (PBDE) flame retardants and environmental and behavioral factors in pregnant women. $J$ Expo Sci Environ Epidemiol 2013, 23:176-182.

6. Herbstman JB, Sjodin A, Kurzon M, Lederman SA, Jones RS, Rauh V, Needham LL, Tang D, Niedzwiecki M, Wang RY, Perera F: Prenatal exposure to PBDEs and neurodevelopment. Environ Health Perspect 2010, 118(5):712-719.

7. Johnson PI, Stapleton HM, Mukherjee B, Hauser R, Meeker JD: Associations between brominated flame retardants in house dust and hormone levels in men. Sci Total Environ 2013, 445-446:177-184.

8. Kim J, Kang JH, Park H, Baek SY, Kim YH, Chang YS: Assessment of polybrominated diphenyl ethers (PBDEs) in serum from the Korean general population. Environ Pollut 2012, 164:46-52.

9. Kalantzi Ol, Geens T, Covaci A, Siskos PA: Distribution of polybrominated diphenyl ethers (PBDEs) and other persistent organic pollutants in human serum from Greece. Environ Int 2011, 37:349-353.

10. Vizcaino E, Grimalt JO, Lopez-Espinosa MJ, Llop S, Rebagliato M, Ballester F: Polybromodiphenyl ethers in mothers and their newborns from a non-occupationally exposed population (Valencia, Spain). Environ Int 2011, 37:152-157.

11. Knutsen HK, Kvalem HE, Thomsen C, Froshaug M, Haugen M, Becher G, Alexander J, Meltzer HM: Dietary exposure to brominated flame retardants correlates with male blood levels in a selected group of Norwegians with a wide range of seafood consumption. Mol Nutr Food Res 2008, 52:217-227.

12. Sjodin A, Wong LY, Jones RS, Park A, Zhang Y, Hodge C, Dipietro E, McClure C, Turner W, Needham LL, Patterson DG Jr: Serum concentrations of polybrominated diphenyl ethers (PBDEs) and polybrominated biphenyl (PBB) in the United States population: 2003-2004. Environ Sci Technol 2008, 42(4):1377-1384.

13. Hites RA: Polybrominated diphenyl ethers in the environment and in people: a meta-analysis of concentrations. Environ Sci Technol 2004, 38:945-956.

14. Salihovic S, Lampa E, Lindstrom G, Lind L, Lind PM, van Bavel B: Circulating levels of persistent organic pollutants (POPs) among elderly men and women from Sweden: results from the Prospective Investigation of the Vasculature in Uppsala Seniors (PIVUS). Environ Int 2012, 44:59-67.

15. Martiny WY, Miteva MA: Advances in Molecular Modeling of Human Cytochrome P450 Polymorphism. J Mol Biol 2013, 425:3978-3992.

16. Staskal DF, Hakk H, Bauer D, Diliberto JJ, Birnbaum LS: Toxicokinetics of polybrominated diphenyl ether congeners 47, 99, 100, and 153 in mice. Toxicol Sci 2006, 94:28-37.

17. Yuan ZH, Liu Q, Zhang Y, Liu HX, Zhao J, Zhu P: CYP2B6 gene single nucleotide polymorphisms and leukemia susceptibility. Ann Hematol 2011, 90:293-299.

18. Erratico CA, Szeitz A, Bandiera SM: Biotransformation of 2,2',4,4'tetrabromodiphenyl ether (BDE-47) by human liver microsomes: identification of cytochrome P450 2B6 as the major enzyme involved. Chem Res Toxicol 2013, 26:721-731.

19. Feo ML, Gross MS, McGarrigle BP, Eljarrat E, Barcelo D, Aga DS, Olson JR: Biotransformation of BDE-47 to potentially toxic metabolites is predominantly mediated by human CYP2B6. Environ Health Perspect 2013, 121:440-446.

20. Wahl M, Lahni B, Guenther R, Kuch B, Yang L, Straehle U, Strack S, Weiss C: A technical mixture of 2,2',4,4'-tetrabromo diphenyl ether (BDE47) and brominated furans triggers aryl hydrocarbon receptor (AhR) mediated gene expression and toxicity. Chemosphere 2008, 73:209-215.

21. McGraw J, Waller D: Cytochrome P450 variations in different ethnic populations. Expert Opin Drug Metab Toxicol 2012, 8:371-382.

22. Lang T, Klein K, Fischer J, Nussler AK, Neuhaus P, Hofmann U, Eichelbaum $M$, Schwab M, Zanger UM: Extensive genetic polymorphism in the human CYP2B6 gene with impact on expression and function in human liver. Pharmacogenetics 2001, 11:399-415.

23. Li J, Menard V, Benish RL, Jurevic RJ, Guillemette C, Stoneking M, Zimmerman PA, Mehlotra RK: Worldwide variation in human drugmetabolism enzyme genes CYP2B6 and UGT2B7: implications for HIV/AIDS treatment. Pharmacogenomics 2012, 13:555-570.

24. Preissner SC, Hoffmann MF, Preissner R, Dunkel M, Gewiess A, Preissner S: Polymorphic Cytochrome P450 Enzymes (CYPs) and Their Role in Personalized Therapy. PLoS One 2013, 8:e82562.
25. Jinno H, Tanaka-Kagawa T, Ohno A, Makino Y, Matsushima E, Hanioka N, Ando M: Functional characterization of cytochrome P450 2 B6 allelic variants. Drug Metab Dispos 2003, 31:398-403.

26. Jacobs ET, Van Pelt C, Forster RE, Zaidi W, Hibler EA, Galligan MA, Haussler MR, Jurutka PW: CYP24A1 and CYP27B1 polymorphisms modulate vitamin D metabolism in colon cancer cells. Cancer Res 2013, 73:2563-2573.

27. Davaalkham J, Hayashida T, Tsuchiya K, Gatanaga H, Nyamkhuu D, Oka S: Allele and genotype frequencies of cytochrome P450 2B6 gene in a Mongolian population. Drug Metab Dispos 2009, 37:1991-1993.

28. Wang SC, Ho IK, Tsou HH, Tian JN, Hsiao CF, Chen CH, Tan HK, Lin L, Wu CS, Su LW, Huang CL, Yang YH, Liu ML, Lin KM, Chen CY, Liu SC, Wu HY, Chan HW, Tsai MH, Lin PS, Liu YL: CYP2B6 polymorphisms influence the plasma concentration and clearance of the methadone S-enantiomer. J Clin Psychopharmacol 2011, 31(4):463-469.

29. Dobrinas M, Crettol S, Oneda B, Lahyani R, Rotger M, Choong E, Lubomirov R, Csajka C, Eap CB: Contribution of CYP2B6 alleles in explaining extreme (S)-methadone plasma levels: a CYP2B6 gene resequencing study. Pharmacogenet Genomics 2013, 23:84-93.

30. Carr DF, la Porte CJ, Pirmohamed M, Owen A, Cortes CP: Haplotype structure of CYP2B6 and association with plasma efavirenz concentrations in a Chilean HIV cohort. J Antimicrob Chemother 2010, 65:1889-1893.

31. Lind L, Fors N, Hall J, Marttala K, Stenborg A: A comparison of three different methods to evaluate endothelium-dependent vasodilation in the elderly: the Prospective Investigation of the Vasculature in Uppsala Seniors (PIVUS) study. Arterioscler Thromb Vasc Biol 2005, 25:2368-2375.

32. Sandau CD, Sjodin A, Davis MD, Barr JR, Maggio VL, Waterman AL, Preston KE, Preau JL Jr, Barr DB, Needham LL, Patterson DG Jr: Comprehensive solidphase extraction method for persistent organic pollutants. Validation and application to the analysis of persistent chlorinated pesticides. Anal Chem 2003, 75(1):71-77.

33. Salihovic S, Mattioli L, Lindstrom G, Lind L, Lind PM, van Bavel B: A rapid method for screening of the Stockholm Convention POPs in small amounts of human plasma using SPE and HRGC/HRMS. Chemosphere 2012, 86:747-753.

34. Succop PA, Clark S, Chen M, Galke W: Imputation of data values that are less than a detection limit. J Occup Environ Hyg 2004, 1:436-441.

35. Glass DC, Gray CN: Estimating mean exposures from censored data: exposure to benzene in the Australian petroleum industry. Ann Occup Hyg 2001, 45:275-282.

36. Zoffoli HJ, Varella CA, do Amaral-Sobrinho NM, Zonta E, Tolon-Becerra A: Method of median semi-variance for the analysis of left-censored data: comparison with other techniques using environmental data. Chemosphere 2013, 93:1701-1709.

37. Rylander L, Nilsson-Ehle P, Hagmar L: A simplified precise method for adjusting serum levels of persistent organohalogen pollutants to total serum lipids. Chemosphere 2006, 62:333-336.

38. Staskal DF, Diliberto JJ, DeVito MJ, Birnbaum LS: Toxicokinetics of BDE 47 in female mice: effect of dose, route of exposure, and time. Toxicol SCi 2005, 83:215-223.

39. Sueyoshi T, Li L, Wang H, Moore R, Kodavanti PR, Lehmler HJ, Negishi M, Birnbaum LS: Flame Retardant BDE-47 Effectively Activates Nuclear Receptor CAR in Human Primary Hepatocytes. Toxico/ Sci 2014, 137:292-302.

40. Weiss J, Haefeli WE: Potential of the novel antiretroviral drug rilpivirine to modulate the expression and function of drug transporters and drug-metabolising enzymes in vitro. Int J Antimicrob Agents 2013, 41:484-487.

41. Ericsson T, Masimirembwa C, Abelo A, Ashton M: The evaluation of CYP2B6 inhibition by artemisinin antimalarials in recombinant enzymes and human liver microsomes. Drug Metab Lett 2012, 6:247-257.

42. Kharasch ED, Stubbert K: Role of cytochrome P4502B6 in methadone metabolism and clearance. J Clin Pharmacol 2013, 53:305-313.

43. Dickmann L, VandenBrink BM, Lin YS: In vitro hepatotoxicity and cytochrome P450 induction and inhibition characteristics of carnosic acid, a dietary supplement with antiadipogenic properties. Drug Metab Dispos 2012, 40:1263-1267.

44. Klein K, Lang T, Saussele T, Barbosa-Sicard E, Schunck WH, Eichelbaum M, Schwab M, Zanger UM: Genetic variability of CYP2B6 in populations of African and Asian origin: allele frequencies, novel functional variants, and possible implications for anti-HIV therapy with efavirenz. Pharmacogenet Genomics 2005, 15:861-873. 
45. Sukasem C, Manosuthi W, Koomdee N, Santon S, Jantararoungtong T, Prommas S, Chamnanphol M, Puangpetch A, Sungkanuparph S: Low level of efavirenz in HIV-1-infected Thai adults is associated with the CYP2B6 polymorphism. Infection 2013, Nov 30:Epub ahead of print.

46. Sukasem C, Manosuthi W, Koomdee N, Santon S, Jantararoungtong T, Prommas S, Chamnanphol M, Puangpetch A, Sungkanuparph S: Low level of efavirenz in HIV-1-infected Thai adults is associated with the CYP2B6 polymorphism. Infection 2013, 2013: Epub ahead of print.

47. Desta Z, Saussele T, Ward B, Blievernicht J, Li L, Klein K, Flockhart DA, Zanger UM: Impact of CYP2B6 polymorphism on hepatic efavirenz metabolism in vitro. Pharmacogenomics 2007, 8:547-558.

48. Kwara A, Lartey M, Sagoe KW, Rzek NL, Court MH: CYP2B6 (c.516G $\rightarrow$ T) and CYP2A6 $(* 9 B$ and/or *17) polymorphisms are independent predictors of efavirenz plasma concentrations in HIV-infected patients. Br J Clin Pharmacol 2009, 67:427-436.

49. Mastrogianni O, Gbandi E, Orphanidis A, Raikos N, Goutziomitrou E, Kolibianakis EM, Tarlatzis BC, Goulas A: Association of the CYP2B6 c.516G $>$ T polymorphism with high blood propofol concentrations in women from northern Greece. Drug Metab Pharmacokinet 2013, Epub ahead of print.

50. Justenhoven C, Pentimalli D, Rabstein S, Harth V, Lotz A, Pesch B, Bruning T, Dork T, Schurmann P, Bogdanova N, Park-Simon TW, Couch FJ, Olson JE, Fasching PA, Beckmann MW, Haberle L, Ekici A, Hall P, Czene K, Liu J, Li J, Baisch C, Hamann U, Ko YD, Brauch H: CYP2B6*6 is associated with increased breast cancer risk. Int J Cancer 2014, 134(2):426-430.

51. Bloom AJ, Martinez M, Chen LS, Bierut LJ, Murphy SE, Goate A: CYP2B6 non-coding variation associated with smoking cessation is also associated with differences in allelic expression, splicing, and nicotine metabolism independent of common amino-acid changes. PLoS One 2013, 8:e79700.

52. Mikstacki A, Skrzypczak-Zielinska M, Tamowicz B, Zakerska-Banaszak O, Szalata M, Slomski R: The impact of genetic factors on response to anaesthetics. Adv Med Sci 2013, 58:9-14.

53. Wang $H$, Tompkins LM: CYP2B6: new insights into a historically overlooked cytochrome P450 isozyme. Curr Drug Metab 2008, 9:598-610.

54. Ring HZ, Valdes AM, Nishita DM, Prasad S, Jacob P 3rd, Tyndale RF, Swan GE, Benowitz NL: Gene-gene interactions between CYP2B6 and CYP2A6 in nicotine metabolism. Pharmacogenet Genomics 2007, 17:1007-1015.

55. Miksys $S$, Tyndale RF: The unique regulation of brain cytochrome P450 2 (CYP2) family enzymes by drugs and genetics. Drug Metab Rev 2004, 36:313-333.

doi:10.1186/1476-069X-13-34

Cite this article as: Penell et al: Genetic variation in the CYP2B6 Gene is related to circulating 2,2',4,4'-tetrabromodiphenyl ether (BDE-47)

concentrations: an observational population-based study. Environmental Health 2014 13:34.

\section{Submit your next manuscript to BioMed Central and take full advantage of:}

- Convenient online submission

- Thorough peer review

- No space constraints or color figure charges

- Immediate publication on acceptance

- Inclusion in PubMed, CAS, Scopus and Google Scholar

- Research which is freely available for redistribution 